\title{
THE ANALYSIS OF PHYTOPHAGOUS MAMMALS' EXCRETORY ACTIVITY IN FOREST ECOSYSTEMS
}

(C) 2017

Pilipko Yelena Nikolaevna, candidate of biological sciences, associate professor of Forestry Department Vereshchagin Vologda State Dairy Farming Academy (Vologda, Russian Federation)

Abstract. In this paper the author considers the excretory activity as one of zoocenosis environment-transforming activity types. The paper presents the results of experimental data on the effect of phytophagous animals' excreta on the soil-forming processes through adding organic substances to the soil in the process of decomposing the undigested plant residues. The organic substance (humus) is a source of mineral elements necessary for plant organisms. The value of phytophagous animals' excreta is in their peculiar properties such as high content of humic acids performing a number of important functions in the biosphere. In this paper one of these functions - accumulative - has been considered. Decomposition of the organic substance in the form of the excreta of the elk (Alces alces, L.) as the largest phytophagous animal of the north-west proceeded in the course of the experiment in natural and laboratory conditions. Anthropogenically disturbed areas of the Vologda Region have been chosen as natural conditions. The excreta decomposition took place on medium-loamy and strongly podzolic soils on the cutting site after clear felling in the sorrel spruce forest. In laboratory conditions the experiments on excreta decomposition have been carried out in microlysimeters. Thereby we have chosen the three factor experiment with subsequent developing mathematical models (regression equations). We have used the winter variety of the elk's excreta which differs in composition from the summer variety. Winter excreta appear as a result of digesting the coarse woody feeds. In the paper the results of the research on the group composition of humus and agrochemical NPK-complex have been given. As a result of decomposition it has been revealed that the content of the humus components under study and NPK have been influenced by the size of particles in the soil, microconditions and the time of organic substance decomposition.

Keywords: zoocenosis; phytophagous animals; excreta; humus; aggregate carbon; carbon of humic and fulvic acids; unhydrolyzed remainder; NPK-complex; nitrates; phosphates; potassium; field and laboratory experiment; microlysimeters; anthropogenic load; cutting sites; three factor experiment; regression equation; loamy soils; loamy sands.

\section{ВЛИЯНИЕ ВЕЛИЧИНЫ СНЕЖНОГО ПОКРОВА И СУРОВОСТИ КЛИМАТА НА ПОВЕДЕНЧЕСКИЕ АДАПТАЦИИ ЛИСИЦЫ ОБЫКНОВЕННОЙ (VULPES VULPЕS)}

\section{(C) 2017}

Склюев Валерий Витальевич, кандидат биологических наук, декан химико-биологического факультета Склюева Ольга Александровна, аспирант кафедры экологии и охраны окружающей среды Самарская государственная областная академия (Наяновой) (г. Самара, Российская Федерация)

Аннотаџия. Одним из способов приспособления к изменяющимся параметрам внешней среды являются поведенческие адаптации. В работе приведены данные по применению показателя жесткости погоды по Г. Бодману в экологических исследованиях. Описаны поведенческие особенности активности лисицы обыкновенной (Vulpes vulpes, Linnaeus, 1758) в зависимости от величины снежного покрова и суровости климата на примере территории Красноармейского района Самарской области. При относительно небольшой отрицательной температуре, но достаточно большой скорости ветра теплопотери животного будут выше, чем при большой отрицательной температуре в безветренную погоду. В литературе (Формозов А.Н. 1946 [1], 1990 [2]) есть указания на возможность использования показателя жесткости погоды, определяющего условия, способствующие обморожению [2; 3]. Он определяется низкой температурой воздуха и скоростью ветра, особенно влияющими на охлаждение объектов, которые обладают избыточным теплом по сравнению с окружающей средой. Однако в этом же источнике [2; 3] автор (Формозов А.Н.) не мог использовать данный показатель в связи с достаточно большими отклонениями как по скорости ветра (определяющее значение), так и по температуре на исследуемой им территории, так как даже на одной местности существует несовпадение с данными метеостанций, расположенных удаленно друг от друга, а самостоятельных измерений в исследуемых биотопах автор не проводил [1-3]. Вместе с тем отмечается и чрезвычайная важность фактора снежности - как мощного элемента среды, отсеивающего жизненные формы, пригодные или непригодные к существованию в обширных областях со снежной зимой [1-3], затрудняющего движение, доступ к кормам. Снежный покров вызывает сезонные миграции у одних форм или сезонную изменчивость режима питания (переход на корма, находящиеся над снегом) - у других.

Ключевые слова: показатель жесткости погоды; суровость климата; снежный покров; экологические исследования; лисица обыкновенная (Vulpes vulpes); поведенческая активность; поведенческие адаптации; показатель Бодмана; зимние тропления следов млекопитающих; экологическая пластичность.

\section{Цель работы}

Определение влияния фактора снежности на поведенческие адаптации лисицы обыкновенной ( $\mathrm{Vul}$ - pes vulpes), рассмотрение возможности применения показателя жесткости погоды в экологических исследованиях. 
Склюев В.В., Склюева О.А.

\section{Задача исследования.}

1) выявить различия в поведенческой активности лисицы в зависимости от величины снежного покрова и суровости климата; 2) апробировать применение показателя жесткости погоды по Г. Бодману в экологических исследованиях.

\section{Материальи и методы.}

Учитывая наличие ручного анемометра (определяющее значение) и термометра, провести подробные измерения ветротемпературных параметров на интересующей нас местности не составляло особого труда. Ночные измерения проводились в 22:0023:00; утренние - 07:00-09:00; особую роль играли дневные измерения (с несколькими повторами) с 12:00 до 14:00 непосредственно в биотопах, где проводилось тропление. На основании проведенных измерений был произведен расчет показателя Бодмана для исследуемой территории. Суровость климата измерялась в баллах по формуле Г. Бодмана:

$$
S=(1-0,04 t)(1+0,272 \mathrm{~V}),
$$

где: $\mathrm{S}$ - баллы суровости; $\mathrm{t}$ - средняя температура воздуха за период наблюдения, ${ }^{\circ} \mathrm{C} ; \mathrm{V}$ - средняя скорость ветра за период наблюдения, м/с.

Зимний период 2009-2010 года был наиболее благоприятен для исследования полоспецифичности поведенческой активности в зависимости от величины снежного покрова и суровости климата в пределах исследуемого биотопа. При проведении исследования в декабре-феврале 2010 г. средняя величина снежного покрова на полях составляла 20-30 см (с приблизительно 20 см в декабре, до $30 \mathrm{~cm} \mathrm{-} \mathrm{в} \mathrm{феврале),}$ как правило не превышая 30 см [4].

В конце февраля - начале марта после продолжительных снегопадов величина снежного покрова на полях составила более 50 см (до 60 см), в овражках, низинах, буераках толщина снежного покрова была от $80 \mathrm{~cm}$ (овражки, низины) до $120 \mathrm{~cm}$ (углубления, буераки) против 30 см в январе - феврале в низинах и овражках и не более $50 \mathrm{~cm}$ - в углублениях и буераках. Необходимо отметить, что, в целом, весь район исследования располагался на местности с понижением ландшафта [4].

Данные по поведенческим реакциям собирались методом зимних (детальных) троплений следов млекопитающих [5-8].

Результаты и обсуждение.

Проводимые наблюдения, в том числе и по величине снежного покрова, хорошо согласуются с прогнозами метеорологических служб [9]: в феврале характер погоды существенно не изменился. Средняя за месяц температура воздуха почти повсеместно оказалась ниже обычной на $1,0-3,5^{\circ} \mathrm{C}$. Количество выпавших в феврале осадков на юге, юго-востоке и северо-западе европейской территории страны оказалась в 1,3-1,8 раза, на западе местами почти в 3 раза больше нормы [9]. Автор считает целесообразным привести еще одну выдержку из сообщения самарских СМИ за 2010 г. [10]: «В Самарской области складывается крайне сложная ситуация: конец марта, а снег еще не растаял. Более того, за последние дни величина снежного покрова увеличилась до 12 сантиметров. Ожидается интенсивный паводок» [10].
Приведенные выдержки из разных источников хорошо согласуются с результатами авторских наблюдений как за толщиной снежного покрова, так и за сроками выпадения большого количества снега в марте. Особо стоит отметить большую величину снежного покрова в районе р. Чапаевка. Однако, вместе с особенностями снежного покрова, показания температуры, и особенно скорости ветра, имеют важное значение для всех животных исследуемых территорий, в связи с определяющим влиянием на величину теплопотерь. Например, в проведенных расчетах с использованием показателя Бодмана в Красноармейском районе Самарской области, при температуре воздуха $+1^{\circ} \mathrm{C}$ и скорости ветра $10 \mathrm{~m} / \mathrm{c}$ величина теплопотери оказалась выше, чем при температуре -14 и ветре $1 \mathrm{~m} / \mathrm{c}$ (3 балла против 2) [4].

В наших расчетах использовались усредненные за сутки (определяющими были тем не менее результаты измерения непосредственно на местности). По результатам подсчета был построен график (рис. 1). Стоит отметить, что измерения проводились по 7 дней - с 7 по 14 февраля (3,1 - средний балл за 7 дней) и с 12 по 18 марта (средний балл - 2,4), после значительного увеличения величины снежного покрова в начале марта. Самое высокое значение показателя Бодмана в 2010 г. для исследованной территории составило 3,93 балла при скорости ветра 4 м/с и температуре воздуха $22^{\circ} \mathrm{C}$ в ночь на 9 февраля.

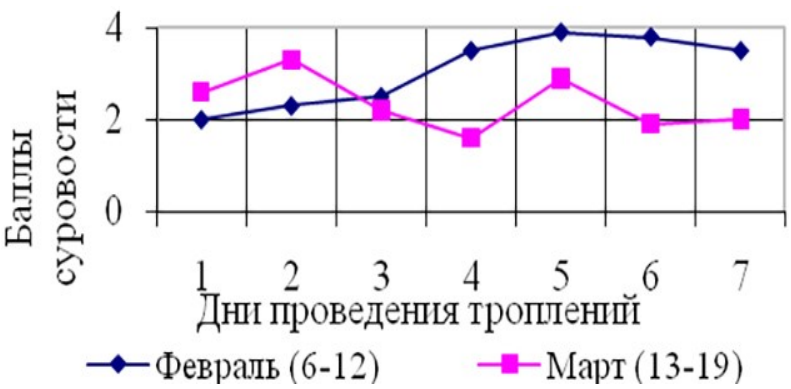

Рисунок 1 - График динамики показателя жесткости погоды во время проведения троплений (по [4])

Полученные данные хорошо согласуются с метеосводками по региону и значительно дополняют их на местности. В целом, большинство точек лежит в области значений, характерных для среднеширотной зоны. Исходя из собственных расчетов и измерений, автор считает возможным оценить значения индекса условий как среднесуровые, а не малосуровые (как, в частности, указывалось в работе М.В. Исаевой [11].

На основании проведенных исследований с фиксацией всех проявлений двигательной активности по оставленным следам на снегу была построена таблица (табл. 1).

Интересно отметить, что самки предпочитают участки с наиболее разнообразными эдафическими условиями, на данной местности это зачастую участки с овражками, однако, по наблюдениям, мышкование в многоснежный период производится по склону овражка, у травяных кочек по периметру, часто самки заходят на участки самцов [4; 12-14]. При этом изменяется общая площадь участка - участок становится значительно меньше, в том числе и в области перекрывания, видимо, в связи с трудностью в передвижении по глубокому снегу. Интересно отметить, что самки используют свои следы для передвижения 
в два раза чаще, чем самцы (возможно, в связи с тем, что в овражках глубина снежного покрова выше, чем на открытых участках, даже в малоснежный период, a, по литературным данным, площадь лап лисицы невелика [1-3]). В частности, в литературе имеются указания на переоцененность приспособленности лисицы к жизни в многоснежных областях [1].
Виды с малой опорной поверхностью конечностей, вынужденные двигаться по рыхлому снегу (рис. 2), будут находиться в менее благоприятных условиях.

Легко ломающаяся взвешенная ледяная корка наст (рис. 2) мешает хищнику бесшумно подкрадываться к осторожной жертве, режет лапы, затрудняет передвижение и заставляет менять места охоты [1-3].

Таблица 1 - Полоспецифические различия в поведенческих реакциях лисицы обыкновенной по данным зимних троплений в малоснежные и многоснежные периоды, формализованные в виде двигательных реакций на 1000 м следовой дорожки

\begin{tabular}{|c|c|c|c|c|c|c|c|c|c|c|c|c|c|c|}
\hline $\begin{array}{c}\text { Поло- } \\
\text { вая } \\
\text { принад- } \\
\text { леж- } \\
\text { ность }\end{array}$ & $\begin{array}{c}\text { Сум- } \\
\text { ма } \\
\text { всех } \\
\text { реак- } \\
\text { ций }\end{array}$ & $\begin{array}{c}\text { Сумма } \\
\text { двига- } \\
\text { тельных } \\
\text { реакций }\end{array}$ & $\begin{array}{c}\text { Локо- } \\
\text { мотор- } \\
\text { ные ре- } \\
\text { акции }\end{array}$ & $\left|\begin{array}{c}\text { Смена } \\
\text { аллю- } \\
\text { ра }\end{array}\right|$ & $\begin{array}{c}\text { Ос- } \\
\text { та- } \\
\text { нов- } \\
\text { ки }\end{array}$ & $\begin{array}{c}\text { Ориен- } \\
\text { тиро- } \\
\text { вочные } \\
\text { реак- } \\
\text { ции }\end{array}$ & $\begin{array}{c}\text { Иссле- } \\
\text { дова- } \\
\text { тель- } \\
\text { ские } \\
\text { реак- } \\
\text { ции } \\
\end{array}$ & $\begin{array}{c}\text { Пас- } \\
\text { сивно- } \\
\text { оборо- } \\
\text { ни- } \\
\text { тель- } \\
\text { ные } \\
\end{array}$ & $\begin{array}{c}\text { Поис- } \\
\text { ково- } \\
\text { пище- } \\
\text { вые }\end{array}$ & $\begin{array}{l}\text { Пи- } \\
\text { ще- } \\
\text { вые }\end{array}$ & $\begin{array}{l}\text { Тер- } \\
\text { рито- } \\
\text { ри- } \\
\text { аль- } \\
\text { ные }\end{array}$ & $\begin{array}{c}\text { Ком- } \\
\text { му- } \\
\text { ни- } \\
\text { ка- } \\
\text { ции }\end{array}$ & $\begin{array}{c}\text { Реак- } \\
\text { ции } \\
\text { дис- } \\
\text { ком- } \\
\text { форта }\end{array}$ & $\begin{array}{c}\text { Под- } \\
\text { ража- } \\
\text { тель- } \\
\text { ные }\end{array}$ \\
\hline \multirow{2}{*}{$q$} & 628 & & N & 58 & 48 & 73 & 48 & 58 & 11 & 2 & 44 & 34 & - & 14 \\
\hline & 481 & 214 & 92 & 57 & 65 & 19 & 31 & 11 & 126 & 19 & - & 8 & 53 & - \\
\hline \multirow[b]{2}{*}{0} & 287 & & 76 & 4 & 42 & 12 & 23 & 34 & 3 & 8 & 46 & 7 & - & - \\
\hline & 506 & 261 & 125 & 40 & 96 & 46 & 41 & 38 & 74 & 2 & 10 & 22 & 6 & 6 \\
\hline
\end{tabular}

Примечание. Серой заливкой отмечены данные для многоснежного периода

В литературе отмечено, что только наличие накопленных с осени небольших жировых резервов, способность долго питаться отбросами и переносить длительное голодание дают возможность этому хищнику существовать в условиях ландшафта, бедного дичью и отличающегося многоснежными и продолжительными зимами. Автор же данной работы склонен полагать, что повсеместная встречаемость лисицы (кроме областей Крайнего Севера) объясняется высокой экологической пластичностью вида, а не малой массой тела и в связи с этим успешностью мышкования в условиях глубокого снежного покрова (согласно наблюдениям, это не так), и тем более не только небольшими жировыми резервами. Здесь стоит отметить как влияние антропогенного фактора, так и способность лисицы к активному использованию объектов антропогенной природы (питанию разнообразными кормами (раскапывание навозных куч, раскапывание шкур животных и пр.), использование при передвижении различных объектов антропогенной природы (но не только лисица использует объекты антропогенной природы).

По наблюдениям автора, лисица хорошо проваливается в снег, в частности, стоит отметить сильный рост реакций дискомфорта, что хорошо согласуется с замечанием относительно малой опорной поверхности конечностей этого хищника [1;2].

Полученные данные хорошо согласуются с утверждением, что временные резкие отклонения структуры снежного покрова от нормальной многолетней способны вызывать изменения численности крупных животных и, возможно, даже колебания границ их распространения $[1 ; 2 ; 4]$.

Также, вероятно, по причине трудного передвижения по глубокому снегу для лисицы, уменьшается количество коммуникативных реакций - с 34 до 8 у самок (таблица 1); рост же коммуникаций у самцов, возможно, связан с возросшей активностью самок по краям индивидуальных участков (кроме того, как было показано ранее, самцы начинают использовать следы самок для передвижения, что сказывается на количестве коммуникативных реакций). Уменьше- ние территориальных реакций также, вероятно, зависит от уменьшения общей площади участков в многоснежные периоды. Возможно, что реализация территориального поведения в тяжелых жизненных условиях энергетически нецелесообразна (в т.ч. при погодных условиях, увеличивающих величину теплопотерь - рис. 1). Количество территориальных реакций у самцов и самок приблизительно равно (44 у самок и 46 у самцов), при этом территориальное поведение в малоснежные периоды в условиях высокой численности лисиц исследованной территории направлено на ограничение особей своего пола (самки самок, самцы - самцов). В многоснежные периоды самки не метят свою территорию (другие самки все равно до нее не доходят), но самцы немного реагируют на присутствие в удалении другого самца, а также (в 2 случаях) на покопки самок по периметру участка. Возможно, наличие территориального поведения самцов объяснимо периодом гона и «обострением» территориальности в целом, что хорошо согласуется с литературными источниками [1-4], а также ценностью объектов с потенциальной возможностью реализации поисково-пищевого поведения. Стоит особо отметить увеличение количества поисково-пищевых реакций как у самок, так и у самцов при уменьшении количества пищевых реакций (однозначно удачно завершившейся охотой), что также хорошо согласуется с литературными данными. Следует иметь в виду уникальность полученных автором результатов не столько для данного исследования, сколько с точки зрения задачи исследования именно агроценозов. Данные, приводимые в контексте сравнения, получены другими авторами не только в других районах, но и вне задачи как исследования поведенческих проявлений с целью прогнозирования популяционной устойчивости, так и вне исследования особенностей различных показателей жизни животных в целом для различных сельскохозяйственных угодий, методом знакового поля с целью получения большого практического материала для сравнительного анализа с минимальными финансовыми затратами в короткий срок. 
Склюев В.В., Склюева О.А.

Согласно литературным источникам, основной корм лисицы - мелкие грызуны, в частности полевка обыкновенная. На рис. 3 представлены снимки с запечатленными последствиями реализации поисково- пищевого поведения в начале февраля и во второй половине марта, после оттепели. Хорошо видно увеличение трудоемкости удачной реализации пищевого поведения.

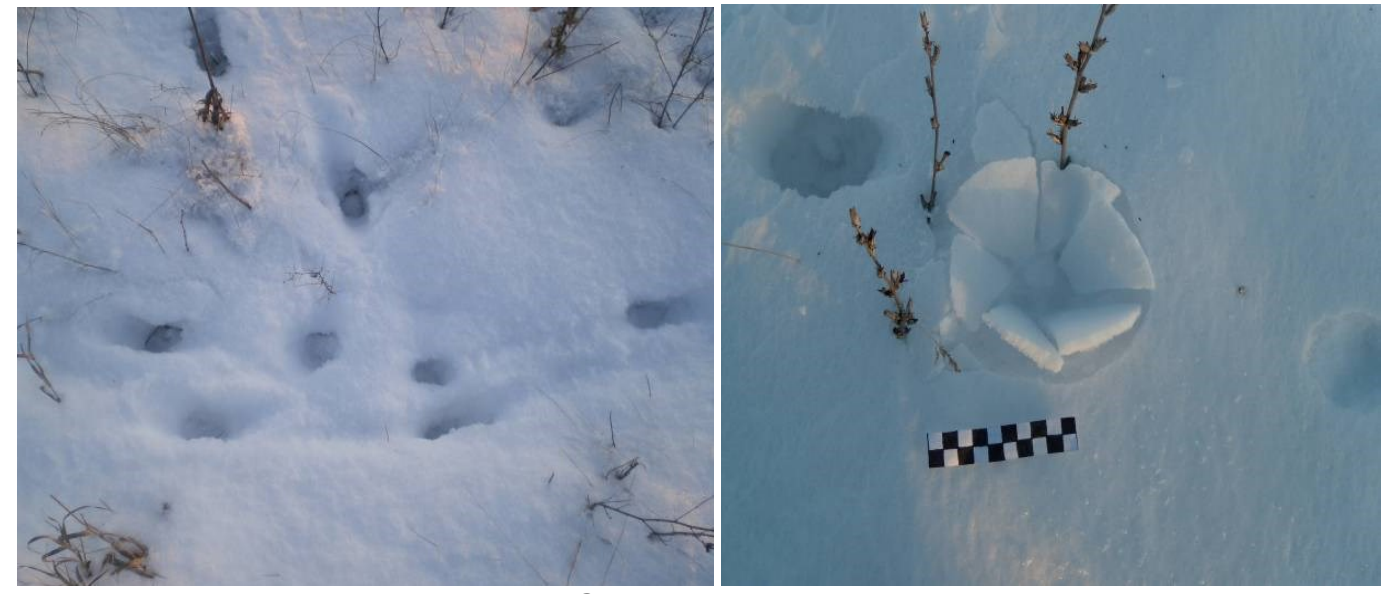

Рисунок 2 - Передвижение лисицы

по рыхлому снегу (слева; величина снежного покрова 20 см; время - 07.01.2009)

и насту (справа; величина снежного покрова 10-15 см, снег плотный; время - 10.03.2009), фото автора
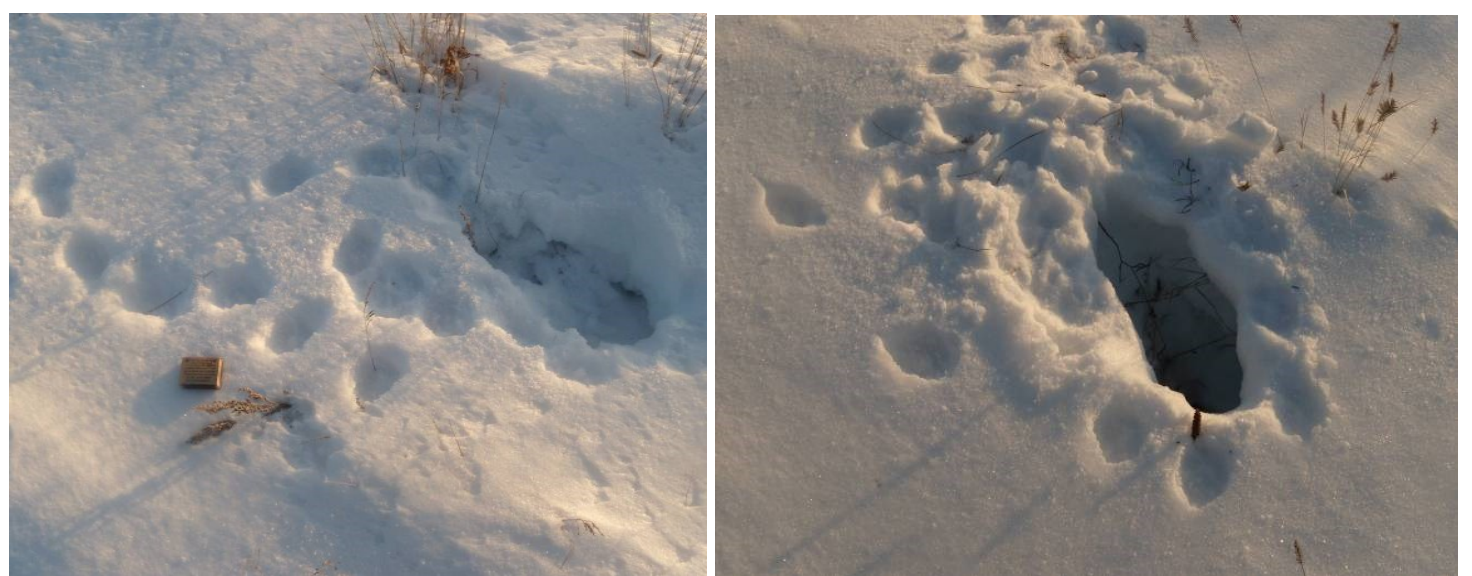

Рисунок 3 - Реализация пищевых реакций. Слева: покопка возле столба. Февраль. Справа: глубокие покопки лисицы (величина снежного покрова более 50 см, наст после оттепели). Март. Фото автора

В многоснежных районах, особенно в некоторые зимы, лисицы в течение недель и месяцев с большим трудом охотятся на мелких зверьков и сильно голодают. В этих условиях они переходят на разного рода вынужденные корма и нередко переносят поиски корма с полей в другие угодья $[1 ; 2]$.

По нашим данным, февраль оказался суровее марта, но в марте были резкие смены температуры (в феврале смена температуры была более плавной см. рис. 1). Март можно считать менее благоприятным для животных исследуемой территории месяцем, в частности, из-за большой величины снежного покрова и образования наста в период небольшой оттепели 12-15 марта. Особо стоит отметить дальнейшее уменьшение успешности мышкования после оттепели. Авторские наблюдения согласуются с литературными данными, согласно которым для лисицы мало определить место, где находится корм, нужно до него добраться, раскопав снег, а это часто стоит больших усилий. Чем выше и плотнее снеговой покров, тем труднее раскапывать его, доставая корм, находящийся на уровне земли. Наблюдения показывают, что для многих животных невысокий снеговой покров, покрытый настом или коркой гололедицы, бывает более опасным, чем сравнительно высокий и рыхлый. После оттепелей и заморозков, когда снег обледеневает, на следах лисицы часто можно видеть кровь пораненных при копании лап (наблюдения А.Н. Формозова в Горьковской области, А.М. Колосова - в Московской области) [3].

Хорошим показателем ухудшения условий охоты лисицы за мышевидными грызунами при оглубении снега служит увеличение процента встреч необычных кормов в желудках [2].

Однако, по нашим наблюдениям, произошло изменение агротехнических мероприятий на исследуемой территории, в связи с чем наблюдается рост численности мышевидных грызунов [15].

Также интересны данные Барановской и Колосова (1935) [16]: по этим данным, зимой 1933/1934 гг. у лисиц Московской области в декабре падаль встречена в 4,55\% желудков, в январе - в 18,6 , в феврале в $27,6 \%$. В феврале же увеличивается и количество встреч съеденных птиц (до 24,7\%), тогда как в другие периоды года они не играют большой роли (мышевидные грызуны в декабре-январе дали 56,8$68,6 \%$ встреч, а в феврале - только $36,5 \%$ ) [2; 16].

В многоснежный период самцы лисицы делают больше глубоких покопок, чем самки. Интересно отметить, что самки более успешны в пищедобывательном поведении, чем самцы, в контексте данного исследования - возможно, из-за отвлечения самцов 
на охрану и мечение территории. Самки чаще используют склон оврага для мышкования. В многоснежные периоды самцы не мышковали на склоне (что не мешало использовать тропы самок - см. подражательное поведение) (табл. 1. Из-за встреч следов лисиц (самцов) соседних участков, самки в малоснежный период активно использовали их для передвижения [17]; из-за уменьшения общей площади участков в многоснежный период чужие следы самками не использовались, то же и с тропами. Собачий след был встречен 1 раз (вообще, в исследуемой территории собаки в снежный период предпочитают перемещаться по автомобильным дорогам либо по часто используемым тропам людей) и, судя по всему, количество реакций на него не зависит от снежности. Объекты территориального характера антропогенной природы, такие как деревня, забор, кладбище, лесополоса, используются в основном как объекты ориентировок. Однако в целом интенсивность ориентировочных реакций, приуроченных к данным объектам, ослабевает, видимо, в связи с уменьшением площади участков. Ослабление территориального поведения (в малоснежный период самцы стараются не выходить за пределы участка, идя по его периметру, как и самки (ослабление территориального поведения самок, предположительно, связано с уменьшением площадей участков в многоснежный период; точнее - с уменьшением «радиуса активности»). В снежный период участок лисицы включает места ночевки, пару лежек и кормовые угодья, в частых ориентировочных реакциях, видимо, животные не нуждаются.

Исследовательские реакции, как и большинство реализованных пищевых (и поисково-пищевых), приурочены к кустарникам (при этом в малоснежный период самцы тяготеют к холмикам, сухой траве (сухостою и травяным кочкам), где, видимо, успешность мышкования была высока и у самок, но из-за, в целом, большего снежного покрова в овражках предпочтение изначально отдавалось кустарнику, однако количество реакций резко возросло (с 10 до 38) в многоснежный период). Самцы же от других объектов перешли к кустарнику [4].

Исследовательские реакции у самцов в снежный период представлены большим количеством двигательных проявлений, возможно, в связи с глубоким снегом (а во второй половине марта еще и настом), укрывшим прежние объекты, к которым были преимущественно приурочены реакции поисково-пищевого характера (травяные кочки, сухостой). У самок наблюдается снижение доли исследовательского поведения, предположительно, в связи с уменьшением площади участка, по мнению автора, та же картина наблюдается и относительно ориентировочных реакций (большинство из которых, видимо, приурочено к поисково-пищевым, однако на практике это утверждение без проведения видеосъемки проверить проблематично). Не удалось выявить корреляции между количеством учтенных остановок и ориентировочным поведением.

\section{Bblводbl.}

1. Изменяется соотношение поведенческих проявлений в зависимости от величины снежного покрова и суровости климата. Увеличивается количество поисково-пищевых при снижении общей доли пищевых (удачно завершившееся пищедобывательное поведение) реакций. Сильно меняется представленность территориальных реакций, что мы объясняем снижением общей энергозатратности поведенческих реакций (несмотря на приближающийся период гона), что особенно показательно для самцов лисицы. Эти и подобные им поведенческие проявления и лежат в основе поведенческих адаптаций на изменения величины снежного покрова и суровости климата.

2. Применение показателя жесткости погоды по Бодману в эколого-этологических исследованиях может значительно обогатить данные результатов экологического мониторинга, в том числе при биоценотических исследованиях, значительно расширить представления об экологической пластичности изучаемого вида, а также адаптивных особенностей животных конкретной территории (в особенности поведенческих адаптаций - в этологических исследованиях).

\section{Заключение}

С учетом жесткости погоды и величины снежного покрова по изменению поведенческой активности определены особенности адаптивного поведения при изменении величины снежного покрова и суровости климата. Применение показателя жесткости погоды по Бодману позволило нам наложить данные метеосводок на данные собственных измерений и проиллюстрировать динамику суровости погоды в исследуемом регионе с целью более обстоятельного анализа специфики поведенческих проявлений в мало- и многоснежные периоды.

\section{СПИСОК ЛИТЕРАТУРЫ:}

1. Формозов А.Н. Снежный покров как фактор среды, его значение в жизни млекопитающих и птиц СССР. М.: Изд-во МОИП, 1946. 152 с.

2. Формозов А.Н. Снежный покров как фактор среды, его значение в жизни млекопитающих и птиц СССР / отв. ред. Е.Н. Матюшкин. 2-е изд. М.: Изд-во МГУ, 1990. $287 \mathrm{c}$.

3. Формозов А.Н. Снежный покров в жизни млекопитающих и птиц. изд. 3. М.: Изд-во ЛКМ, 2010. $288 \mathrm{c}$.

4. Склюев В.В. Популяционный анализ лисицы обыкновенной (Vulpes vulpes) в биотопах Самарской области разной степени нарушенности: Дис. ... канд. биол. наук. Самара. 2010. 220 с.

5. Мозговой Д.П. Информационно-знаковые поля млекопитающих: теория и практика полевых исследований: дис. в форме научного доклада. Самара: Универс-групп, 2005. 50 с.

6. Мозговой Д.П., Розенберг Г.С. Сигнальное биологическое поле млекопитающих: теория и практика полевых исследований. Самара: Самарский ун-т, 1992. 119 c.

7. Мозговой Д.П. Экологические особенности популяций млекопитающих и организация учетов численности // Всесоюзное совещание по проблеме кадастра и учета животного мира. Уфа, АН СССР, 1989. C. 327-328.

8. Формозов А.Н. Спутник следопыта. М.: Изд-во МГУ, 1989. $320 \mathrm{c}$.

9. Справка об ожидаемом характере весеннего половодья 2010 года на реках Российской Федерации 
и предварительный прогноз притока воды в крупные водохранилища во втором квартале [Электронный pecypc] // http://meteoinfo.ru/hydro-spring.

10. ВолгаИнформ. В Самарской области готовятся к сильному половодью [Электронный ресурс] // http://volgainform.ru/allnews/430801.

11. Исаева М.В. Пространственно-временная изменчивость основных биоклиматических показателей на территории Приволжского федерального округа: автореф. дис. ... канд. геогр. наук. Казань, 2009. C. $14-22$.

12. Склюев В.В., Мозговой Д.П. Особенности поведения и динамика численности лисицы обыкновенной (Vulpes vulpes) в Красноармейском районе Самарской области // Вестник Самар. ГУ. Естественнонаучная серия. 2009. № 2 (68). С. 161-166.

13. Склюев В.В. Особенности перекрывания участков лисицы обыкновенной, существенные при картировании территории // Современные проблемы зоологии позвоночных и паразитологии: мат-лы 3 междунар. науч. конф. «Чтения памяти проф. И.И. Бара-
баш-Никифорова», г. Воронеж, 20-21 марта 2011 г. Воронеж, 2011. С. 288-291.

14. Склюев В.В. Полоспецифичные различия в площадях и размещении индивидуальных участков лисицы обыкновенной // Современные проблемы зоологии позвоночных и паразитологии: мат-лы 4 междунар. науч. конф. «Чтения памяти проф. И.И. Барабаш-Никифорова», г. Воронеж, 13-15 апр. 2012 г. Воронеж, 2012. С. 254-257.

15. Склюев В.В. Избыточность кормовой базы как причина уменьшения площадей индивидуальных участков лисицы обыкновенной // Экология, эволюция и систематика животных: мат-лы междунар. науч.-практ. конф. Рязань, 2012. С. 370-372.

16. Барановская Т.Н., Колосов А.М. Питание лисицы // Зоол. журн. 1935. Т. XIV, вып. 3. С. 523-550.

17. Склюев В.В. Исследование состояния популяции лисицы Красноармейского района Самарской области // Изв. Самар. НЦ РАН. 2009. Т. 11, № 1(4). С. 661-665.

\section{SNOW COVER AND THE CLIMATE SEVERITY INFLUENCE ON THE COMMON FOX (VULPES VULPES) BEHAVIORAL ADAPTATION}

\section{(C) 2017}

Skluev Valerij Vitaljevich, candidate of biological sciences, dean of Chemistry and Biology Faculty Sklueva Olga Aleksandrovna, postgraduate student of Ecology and Environmental Protection Department Samara State Regional Academy (Nayanova) (Samara, Russian Federation)

Abstract. One of the ways to adapt to the changing parameters of the environment is behavioral adaptation. The paper presents data on the weather rigidity index use (G. Bodman) in environmental studies. The authors describe the behavioral characteristics of the common fox (Vulpes vulpes, Linnaeus, 1758) activity depending on the amount of snow cover and the climate severity in Krasnoarmeyskiy district of the Samara Region. Relatively low temperature and quite high wind speed influence the heat loss of the animal more than high temperature in calm weather. In scientific literature (A.N. Formozov, 1946, 1990) it's noted that it is possible to use "weather cruelty» indicator that defines the conditions that contribute to frostbite. It is determined by low air temperature and wind velocity that particularly affect cooling objects that have excessive heat in comparison with the environment. However, A.N. Formozov could not use this indicator due to rather large deviations as the wind speed and the temperature on the investigated territory, as even in the same locality there is a discrepancy with the data of weather stations located remotely from each other, this author didn't study habitats independently (A.N. Formozov, 1946, 1990, 2010). At the same time it is also noted that snowfall is an important factor, a powerful element of the environment that indicates what life forms can live in vast areas with snowy winter. Snow cover leads to seasonal migration or switching to food located above the snow.

Keywords: weather rigidity index; harsh climate; snow; environmental studies; common fox (Vulpes vulpes); behavioral activity; behavioral adaptation; Bodman indicator; winter traces of tracking mammals; ecological plasticity.

УДК 58.032

\section{РЕЗУЛЬТАТЫ ГИДРОБОТАНИЧЕСКОГО МОНИТОРИНГА ЧЕРНОВСКОГО ВОДОХРАНИЛИЩА ЗА ПЕРИОД С 1974 ПО 2015 ГОДЫ}

(C) 2017

Соловьева Вера Валентиновна, доктор биологических наук, профессор кафедры биологии, экологии и методики обучения

Самарский государственный социально-педагогический университет (г. Самара, Российская Федераџия)

Аннотащุия. Особенности эксплуатации водохранилищ вызывают необходимость постоянного сбора, анализа и обобщения экологической информации о динамическом состоянии гидроэкосистем с целью прогноза их развития. Важным показателем состояния экосистемы являются процессы зарастания. В работе представлены результаты исследования флоры и растительности Черновского водохранилища в различные годы. Флористическое разнообразие приводится в сравнении с другими водоёмами, гидроботанические данные о которых опубликованы в ряде работ автора статьи. Сравнительный анализ показал, что общий состав флоры водоёмов носит случайный характер, при этом в экологическом спектре отмечается некоторая закономерность, так, для каждого из них характерно небольшое число видов водной флоры и преобладание береговых видов растений. Изучение растительности Черновского водохранилища показало, что за последние 40 лет, с 1974 по 2015 годы, она изменилась по составу доминантов, при этом сохранилось преобладание воздушно- 